\title{
Relevance of Adult Higher Education on Knowledge Management in the Healthcare Sector
}

\author{
Tone Vold ${ }^{1,2}$ and Hanne M. Haave ${ }^{2}$ \\ ${ }^{1}$ NTNU, IØT, Norway \\ ${ }^{2}$ Inland Norway University of Applied Sciences, Business School - Faculty of Economy and \\ Social Sciences, Rena, Norway \\ tone.vold@inn.no \\ hanne.haave@inn.no \\ DOI: 10.34190/EJKM.18.03.004
}

\begin{abstract}
Organizations, including the healthcare sector, are subject to changes in market, technology and regulations. This requires enhanced and different types of knowledge, and has led to an increased demand for adult higher education. However, the competencies required need to be met by the providers of higher education. This article presents a qualitative case study investigating the work relevance of an adult education study bachelor programme for middle managers of the public health sector in Norway. The paper explores how the education has shaped the interplay between the student/practitioner and his/her surroundings. The data in the study have been collected using in-depth interviews. The case study showcases the potential impacts of higher education within public healthcare management in the workplace, also highlighting the factors that are predominant regarding the application and dissemination of formal knowledge in the workplace. The primary findings of this study are that there is an interplay between the form and content of the education, personal capabilities and individual characteristics of the student (employee/health manager), as well as an organizational maturity pertaining to knowledge-management and the exposure to organizational innovation in the broader healthcare system. The case study contributes to the field of knowledge management issues by showing how a study programme can support the development of knowledge management practices in an organization, through focussing on the relevance pronounced through the management practices.
\end{abstract}

Keywords: relevance, higher education, knowledge management practices, healthcare sector, innovativeness

\section{Introduction}

Higher education institutions increasingly offer formal education programmes to work-active adults. We know relatively little about the factors that determine the relevance of these programmes for the workplace and employee, not to mention all ordinary tertiary educational programmes at the bachelor and master levels. One example of the most recent evidence of such a policy interest is the report from the Expert Group on Life-long Learning, commissioned by the Norwegian Ministry of Education and Research (NOU 2019:12, 2019).

In this article, we investigate which factors may determine the work-relevance of an adult-education bachelor programme specifically designed for middle-management employees in the Norwegian healthcare sector. The municipalities in Norway are responsible for elderly homecare and healthcare in nursing homes (Strandquist and Adal, 2011). Through the Coordination Reform from the Norwegian Ministry of Health and Care Services (2009), the municipalities were designated a central role within healthcare. Seeking to establish a more sustainable healthcare system, one of the challenges was to redirect resources from specialized healthcare at hospitals to preventive health activities (Strandquist and Adal, 2011). This led to a demand for more researchbased knowledge on how to shift the attention of management towards new methods for more preventive healthcare at homecare and nursing homes, and less curative and/or palliative care at the hospitals. Improved knowledge management practices will aid the managers in the healthcare sector in meeting the increasingly new responsibilities and impacts on organizational performance in the knowledge-intensive healthcare sector (Kianto, et al., 2016, Sousa, 2019).

For Knowledge Management scholars and practitioners, we hope that this paper contributes to a better understanding of the particularities and complexities that knowledge management practices entail in a setting of a regional public health system under reform.

Against this policy and cognitive backdrop, and in collaboration with Fagakademiet and "The Resource Centre for Reorganization in Municipalities" since 2011, the Norwegian Ministry of Health and Care Services has 
funded a Health Management bachelor programme (HMP) offered to the middle management segment in the healthcare sector by The Inland Norway University of Applied Sciences The question we explore in this paper is what factors most likely have been shaping the uptake and utilization of knowledge gained in the HM programme in question by following and studying three carefully selected programme participants (previous HMP students) in their work environment.

For obvious ethical reasons, the identity of the respondents and the name of the healthcare institution and municipality are not disclosed. Figure 1 below shows the conceptual organization of the case study, illustrating the key constituents of educational relevance at work in our analytical focus: reflective practice, knowledge sharing and Empowering Leadership (EL), thus enabling innovativeness, connective communication and competency planning.

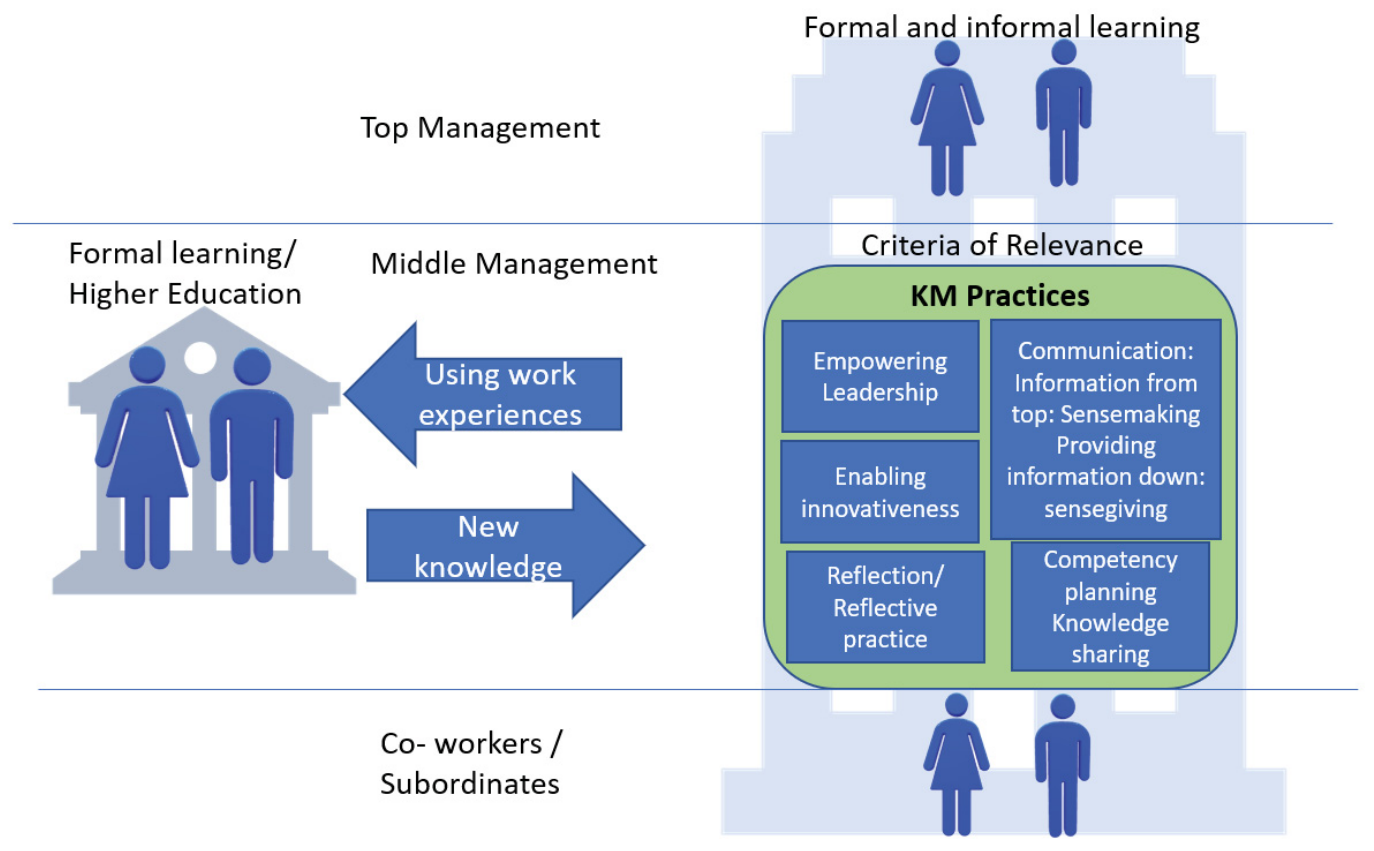

Figure 1: The conceptual framework of the study

The research questions of the study are:

- What are the students' experienced outcomes of the HMP?

- What is the impact of the HMP in the organization?

In the following, we will present the theory that has guided our study, the method of inquiry and the case description. We then present and discuss our results, followed by a conclusion.

\section{Theoretical foundation}

We argue that "relevance" is a dynamic social phenomenon involving actor interactions and sensitive to contextual settings (Hidi and Renninger, 2006, Vold, et al., 2020). As such, it invites the amalgamation of theoretical approaches from different strands of literature in order to comprehend in a meaningful way the findings of our empirical study. We therefore draw theoretical perspectives from disparate research areas such as: adult learning, individual and group learning, learning culture within organizations, reflection and reflective practice, empowering leadership, and of course knowledge management.

Relevance is a keyword in our study. Since an organization is the sum of its members, and depends on learning among the employees in order to learn and develop, it is important to first look at relevance on an individual level. Secondly, we need to establish how personal relevance can be obtained for the relevance to have an impact on the organizational level. Principles on adult education, such as involvement, inclusion and utilizing the students' backgrounds and experiences, contribute toward the relevance and engagement. It also requires reflection processes in order to develop the knowledge into competency. 
For the organization, the relevance will crystalize itself in how the students/employees are able to utilize their knowledge back into the organization, and how they are able to deploy their new knowledge and competencies in order to induce change and innovativeness with their subordinates. Because they are middle managers, it is important to establish any changes in their leadership that have had an impact on the execution of their management and Knowledge Management practices. In order to help define these changes, we need to describe leadership roles within the frames of middle management. It is also interesting to see if there is any meta-learning from the way they have been taught and what they have been taught, which has parallels to whether Empowering Leadership has had any influence on their leadership.

\subsection{Relevance}

Relevance is a term employed somewhat differently in different contexts. Our point of departure is the understanding of relevance as representing value for the work-life, i.e., value either from the employers' or employees' point of view (NOU 2019:12, 2019). We introduce relevance by focussing on the individual learner.

Rogers (1969) claims that "meaningful, experiential learning has relevance to the whole person, has personal involvement, is self-initiated, is pervasive, and is evaluated by the learner" (Schunk, et al., 2014). This means that the students need to have a motivation to attend the education. This motivation may be both intrinsic, as it may be to learn more and develop as a leader, and extrinsic, such as a pay raise or promotion. Not only the learning, but also the relevance, will be evaluated by the learner. The relevance can be tied to relatedness (Roberson, 2013), while the relatedness can be tied to several factors. It may be a teacher who points out some relevance, and provides a context that can be developed into engagement, motivation and selfregulation (Roberson, 2013, Ryan and Deci, 2017)

Relevance is also about achievement-related choices and performances, and how it relates to success expectancies and subjective task values, in which the task values are intrinsic value, attainment value, utility value and cost value. This is described in the expectancy-value model by Eccles (2014). Expectancy is about a person's belief in their own capabilities, and the value is about whether they will be successful (Schunk, et al., 2014). Regarding relevance, utility value corresponds with personal usefulness, whereas attainment value corresponds with identity (Eccles, 2014). An example of expectancy-value intervention is about inviting students to write exercises that relate to their own lives.

Relevance is also discussed from various theories, such as the four-phase model of interest development of Hidi and Renniger (2006). They have defined situational and individual interests, in which individual interest is about being able to engage with a topic or activity over time, while the situational is about having an interest for something and being taught or coming across related topics, topics that are possible to tie to the interest. Their four-phase model depicts how a situational interest can develop into an individual interest. Initially, the situational interest is generally triggered externally through what may be, e.g., learning conditions, such as group work, etc. Phase 2 is where the interest is prolonged through, e.g., meaningful tasks and/or personal involvement, tutoring, etc. Phase 3 is where it is now an emerging personal interest that, through positive feelings, stored knowledge and stored value, arises. Phase 4 is where the interest is often self-generated, and can be long lasting, as it is now well developed. It is in this phase that students begin to pursue their cognitive interests at deeper levels.

The self-efficacy and expectancy-value point to a personal meaningfulness, what Rogers (1969) called relevance. Priniski, et al. (2018) has summed up the personal meaningfulness in a continuum for relevance. An association indicates an indirect meaningfulness. One example of this may be an article on single- and doubleloop learning in a course on organizational theory that also informs a work situation, such as understanding about single- and double-loop learning at the workplace. Personal usefulness is something that may aid in achieving a personal goal, as reading an article may contribute to solving an assignment. The last and most meaningful type of relevance is identification. Thus, learning about leadership styles may support the understanding and identification with that type of leadership.

\subsection{Adult learning}

In order to achieve optimal learning, adults need to be activated (Rogers, 1969). There is now a sufficient body of literature asserting that adult students learn best by being activated (Fezile and Gulsum, 2016, Vold, et al., 2016, Vold, et al., 2017, Vold, 2014), and by being included and involved in the teaching process (Knowles, et al., 2005, Knowles, 1970, Knowles, 1984). 
Including and involving the students in developing the assignments helps to develop a sense of commitment (Filstad, 2016, Nonaka, 1994). The students may draw from their own problem areas at work, work situations and challenges, and discuss and debate real problems with fellow students and with the lecturer. This approach may be experienced as relevant, as many of them are motivated intrinsically or extrinsically to learn more about how to resolve issues at work. Intrinsic motivation is about the motivation that lies in the work execution, whereas extrinsic motivation is the motivation that comes with bonus, pay raises, status, better jobs, etc. (Deci and Ryan, 1985, Ryan and Deci, 2017). The intrinsic motivation stems from two basic needs: 1) the need for self-determination, and 2) the need for the experience of enhanced competency. Deci and Ryan (1985) claim that the intrinsic motivation is "healthiest", as this is tied to an inner desire to perform.

Social cognitive theory describes how one may learn models, skills and/or behaviours, which they may not utilize at the time of the learning, but are still nonetheless able to use them at a later time when they are motivated and/or find the situation appropriate. Bandura expanded the social cognitive theory with his "perceived capabilities to learn or perform action at a designated level" (Schunk, et al., 2014) - also called selfefficacy (Bandura, 1997).

In social cognitive theory, a key assumption is that one can have control over certain events in their lives, and feel a sense of empowerment, self-determination and mastery. Through learning from a teacher, and then practicing and obtaining feedback, they will improve their skills. They also learn from the consequences of their actions, and adapt behaviour according to how they perceive their models. If the models are too flawless, one may not learn and adapt as much as one does from "coping models", in which one's performance improves over time. Reciprocal teaching is also a term in social cognitive theory, and describes how the teacher and students swap roles as teacher-learner (Schunk, et al., 2014). Sometimes, the learner needs time to assume the "teacher role", and the teacher needs to facilitate for the learner to adapt.

The person's judgement of their capabilities to organize and execute tasks, or a person's self-efficacy (Bandura, 1997), may differ, and is enhanced by feedback and the self-evaluation of progress. This also works in groups, with conformity and compliance needed in order to facilitate learning. The teacher may use role models and involve the students. Examples of self-efficacy are about completing the activities necessary for learning, e.g., study goals. Hence, self-efficacy is about the individual's capability of achieving or mastering a task (Bandura, 1986). The individual's own perception of self-efficacy may supersede the measurable abilities. Bandura's social cognitive theory (Bandura, 1986) highlights learning from what one has previously learned. By being provided with examples, they can learn over time to execute the tasks and develop the necessary skills or knowledge to accomplish the work they are supposed to do.

\subsection{Reflective practice and learning culture}

Two major approaches to activating students are using reflection enhancing teaching processes and relevant assignments. Reflection is a major key for learning (Filstad, 2016, Kolb, 1984, Schön, 1987, Schön, 1991). Reflection processes are often tied to experiences, and the experience in a learning setting may often be the assignment, as the assignment can be work related or from the student's actual work-life. Schön (1991) (Schön, 1987) describes reflection processes before, during and after "action", with "action" meaning the students' work experiences.

Reflection processes assume many "shapes": anticipatory and retrospective reflection, critical and emancipatory reflection, reflection in and on action - such as assignments, reflection in action on action, including when testing back in the workplace, self-reflection and reflection for improvement (Ghaye 2007). Moon (2004: p. 80) defined reflection as "a process, that seems to lie somewhere around the notion of learning and thinking. We reflect in order to learn something, or we learn as a result of reflecting - so 'reflective learning' as a notion simply emphasizes the intention to learn as a result of reflection". Dewey (2005) argued for the supremacy of "learning by doing", which implies reflection on the performing activity, i.e., "doing". Kolb (1984) developed this further in his "experiential learning cycle", in which reflection plays a major part. It is the reflection upon action that decides what you take from the action, and defines the basis for the new action.

Filstad (2016) identified some factors that are important when developing a learning culture within an organization (see Figure 2). Developing a common understanding of what constitutes organizational learning is important. It is also necessary to establish how to develop knowledge into competency. 


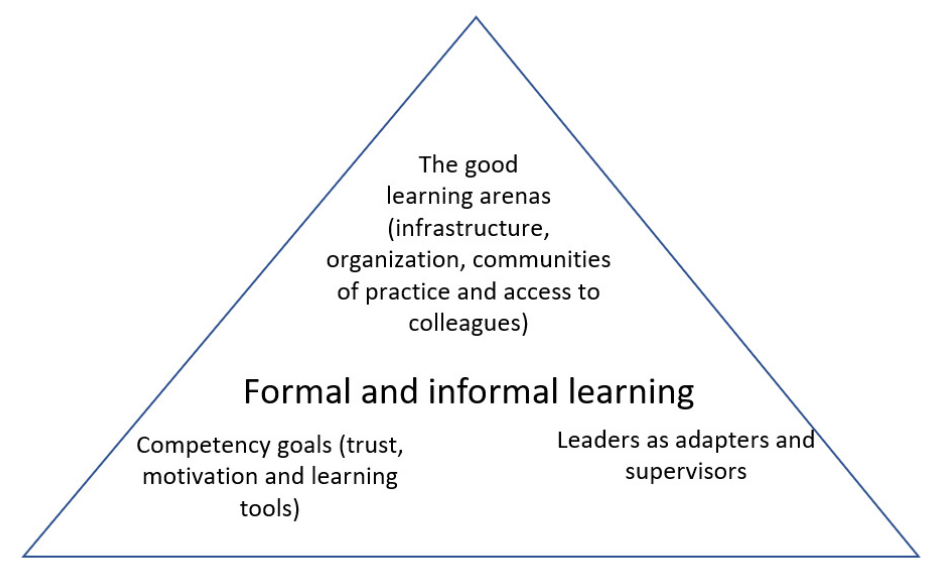

Figure 2: Learning culture (Filstad, 2016)

Learning arenas can be identified as communities of practice and other types of group work within an organization. As the figure shows, goals for competencies may be achieved with trust, motivation and tools for learning. The leaders should function as supervisors in this process, and facilitate for the process of exploiting the learning in both formal and informal learning. There should also be a focus on knowledge sharing and knowledge development throughout the organization.

Formal learning is generally organized and provided by (external) private or public educational institutions, whereas informal learning is learning that takes place in the workplace. It may be in the form of mentorship, Communities of Practice (Lave and Wenger, 1991), learning in teams (Senge, 1992) or something similar. Most of the time, informal learning is not institutionalized and has an instrumental goal. In order to call it learning, it needs to lead to a change in work organization, work behaviour or at least to new detailed knowledge about extant work processes. It is through reflection that learning occurs. The reflections should be about what we do, why we do it and how to find good solutions to problems. Formal learning generally lacks the vivid social and cultural organizational context, and the performative relations present in informal learning settings (Filstad, 2016).

Strategic KM is defined as the: "planning, implementation, and evaluation of initiatives to secure that the organization and each co-worker has and utilizes the necessary competence to achieve defined goals" (Lai, 2013). Lai (2013) also focuses on the term competency, which she defines as: "the collected knowledge, skills, abilities, and attitudes that make it possible to execute the present tasks in line with defined demands and measures". The competencies may be of a formal or informal art, formal being what is learned through education, while informal may be learned at the workplace (Lai, 2013, Raelin, 2008, Filstad, 2016, Irgens, 2011).

Regarding work-based learning, there are three "critical elements" according to Raelin (2008):

- It views learning as acquired in the midst of action and dedicated to the task at hand.

- It sees knowledge creation and utilization as collective activities, wherein learning becomes everyone's job.

- Its users demonstrate a learning-to-learn aptitude, which frees them to question underlying assumptions of practice.

Raelin (2008) claims that work-based learning is different from formal learning initiatives, as it involves a "conscious reflection on actual experience".

The challenge is that the knowledge from the formal setting needs to migrate to- and be practiced in an informal setting in order to become "relevant" learning (Filstad, 2016). According to Filstad (2016), learning in the workplace requires time. However, time is a scarce resource in many organizations. To allocate time for knowledge sharing requires a prioritizing that is sometimes difficult to balance, hence, the importance of managers who prioritize this and point out occasions for knowledge sharing, in addition to facilitating for knowledge-sharing activities. 
Still, it is important that the members of the organization are taking part in this development. This requires enabled subordinates who can make use of the new knowledge and perform innovative behaviour.

Innovation is about developing something new, such as a product, service or organizational method (EUROSTAT, 2005), whereas innovativeness is about being able to contribute actively towards this (Støren and Arnesen, 2016). The OECD (2010) has defined a learning organization, "as an organization that promotes management tools concerned with the improvement of individual and organizational learning" (p. 9). A learning organization, in combination with autonomy among the subordinates, supports innovativeness, which is defined as being able to actively contribute to innovation (Næss, et al., 2009, Støren and Arnesen, 2016, OECD, 2010).

According to the OECD (2010), among the factors influencing innovativeness in the workplace, are a leadership focussing on mastery and an organizational context that embraces changes in customer focus and organizational learning.

\subsection{Empowering middle management}

Mastery is about being enabled to learn, with one of the definitions from Merriam-Webster (2020) being that mastery is a "skill or knowledge that makes one a master of a subject". According to Senge (2006), in organizational learning "personal mastery" enables a person to learn and contribute within an organization. Personal mastery is one of five disciplines that Senge (2006) refers to in a learning organization.

For a leader to obtain this mastery in his or her subordinates, it is important to create and support an environment in which subordinates are supported and encouraged to actively contribute to cultures and relationships within the organization, which enables a utilization of the new knowledge. Woods $(2005$, p. 14) refers to a "Democratic leadership", which "aims to create an environment in which people are empowered and enabled by the institutional, cultural and social structures of the organization". He further states, "Democratic leadership contributes to leaders' and others' growth towards human potential" (Woods, 2005). One example of such leadership is found in the curriculum of the HMP: "Empowering Leadership".

Empowering leadership (EL) is about enabling and supporting subordinates in order to become autonomous through sharing power and delegating responsibility (Amundsen and Martinsen, 2014, Amundsen and Martinsen, 2015, Kim, et al., 2018). Leadership is generally about deciding over and making subordinates execute the orders (Yukl, 2010). EL stands in contrast to the facilitation of making subordinates autonomous, empowering leaders to delegate responsibility, thus giving the subordinates a higher influence regarding their work and sense of autonomy. Empowering leaders through encouragement, positive persuasion and emotional support, and by being role models, can make subordinates feel more included, autonomous and competent (Bandura, 1986, Amundsen and Martinsen, 2014, Amundsen and Martinsen, 2015). To pay attention to the subordinates and listen to their ideas, suggestions and opinions may contribute to their feeling of competency, which in turn may contribute towards the subordinate's ability to make decisions (Amundsen and Martinsen, 2015, Amundsen and Martinsen, 2014). According to Amundsen and Martinsen (2015), the subordinates stand a better chance of improving their work's results.

The subordinates need to lead themselves, and rely on themselves in order to be autonomous. Facilitating EL involves sharing power to help promote the subordinate's energy and effort regarding the handling of autonomy. Therefore, they need to provide motivational support, as well as supporting them in their development of skills and competencies (Amundsen and Martinsen, 2014).

Jacobsen (2019) defines middle management as a "hierarchical position where the leader has some leaders in a level above with more authority and other managers in the level below and with less authority". Consequently, middle management needs to relate to both levels. Yet, according to Jacobsen (2019), there is little research on the role of middle management. Middle management is a communicator of information, and has a role in both strategy processes and change processes (Jacobsen, 2019, Hope, 2015). Top management is generally focused on results, effectiveness, safety and a satisfactory work environment.

On the other hand, middle management plays the role of the "translator", as they "translate" the subordinates' needs and what they consider to be the most vital consequences from different options, synthesizing these into information for top management. Also, when a strategy is decided upon by top 
management, this needs to be "translated" into what this means with regard to new routines and guidelines for the subordinates, which lead to new KM practices.

\subsection{Knowledge Management practices}

Knowledge Management (KM) is about collecting, sharing and utilizing knowledge (Davenport and Prusak, 2000, Davenport and Prusak, 1998). The set of management activities that support the utilization of knowledge in organizations to obtain the best possible effect are called Knowledge Management (KM) practices (Andreeva and Kianto, 2011, Andreeva and Kianto, 2012, Kianto, 2019). The practices should be systematic and intentional to support knowledge sharing and dissemination among the members of an organization. It is also important to note that it is not so much about the practices as such, but more on how the employees perceive and interpret them (Kianto, 2019). Changes may be difficult to induce, and there may be resistance to changes. The resistance may be less over time as the initial "shock" follows a curve that over time ends up in "compliance", meaning they have accepted the change (Irgens, 2011, Hayes, 2002). KM and KM practices are generally applied to support innovation, effectiveness and a competitive advantage (Donate and Sánchez de Pablo, 2015, Nonaka and Takeuchi, 1995, Von Krogh, et al., 2000). KM is also tied to organizational learning. This involves seeing the organization as a system, building and facilitating communities of practice and learning, focussing on personal mastery and personal development and supporting selforganizing within the organization (Davenport and Prusak, 1998).

A precondition for a learning organization is that the individuals learn (Filstad, 2016, Irgens, 2011). As we have described above, the learning arenas can be both formal and informal. When the learning is adapted to adults, this is based on many of the same principles we find in norms from democratic leadership styles. It is about empowering the learner in order to be more autonomous, thereby enabling the learner to feel mastery and being able to be innovative. Consequently, it is important to notice the possibility for both middle managers AND subordinates to learn in the organization by educating the middle managers in Health Organizations. For example, learning about EL will support the leaders to empower not only themselves, but also their subordinates. However, this also requires that the learners (the middle managers) find the curriculum relevant for their work situation, and that they can identify with what is being learned. Learning about EL in a formal setting and learning in an informal setting by experiencing and reflecting (Schön, 1987, Argyris and Schön, 1978, Schön, 1991), together with their peers and with their subordinates, may prepare for innovativeness with their subordinates. It is important to understand how adults learn and what constitutes relevance to them, in order to establish the relevance that enables them to "convert" the knowledge back at the workplace and turning it into competence. We present a theory that will enlighten us on how higher education (HMP) will impact the Knowledge Management (KM) processes in organizations.

Being empowered as subordinates and receiving the motivational support enable the development of skills and competencies, which in turn will affect the Knowledge Management practices within the organization. The middle manager needs to understand the culture and contradictions, and utilize the systems within the organization to guide the subordinates in the knowledge creation process (Holtskog, 2014, Holtskog, et al., 2018). Knowledge-sharing behaviour may also support knowledge-sharing tendencies, as well as strengthening individual performance (Henttonen, et al., 2016). Hence, the management's role in facilitating conditions in which subordinates are willing (and able) to utilize their knowledge and share it with co-workers is important (Sousa, 2019). Nonaka and Takeuchi (2019) support this, as they claim that it is necessary to foster distributed leadership in order to share knowledge within an organization.

\section{Research design and methodology}

We assert that the phenomenon we are investigating in this paper can be best studied by applying a case study methodology. Yin (2009) defines a case study as “..[an] empirical inquiry that investigates a contemporary phenomenon in depth and within its real-life context, especially when the boundaries between phenomenon and context are not clearly evident". Studying work-life relevance of an adult education programme is almost by definition a "contemporary phenomenon", with blurred boundaries with organizational context.

Vold, Haave and Kaloudis (2020) is a previous recent example of a case study investigating the issue of relevance at the workplace of a specific adult education programme of a private Norwegian company. In this paper, we emulate the same methodological approach as in Vold, Haave and Kaloudis (2020), but with some key differences in order to adjust and fully exploit the richness of the case study at hand. 
The purpose of this study is to describe and explore how participation in the specific HMP can qualify as educational activity of relevance for the organizations where the participants are employed. Hence, we do not seek to evaluate whether the learning outcomes of the HMP are achieved in an effective and efficient manner or not. For this type of study, the case study approach allows us to better understand the interplay between HMP learning outcomes and managerial practices within the work-life context by opening the possibility of developing "thick descriptions" of the situation (Geertz, 1973, Remenyi, 2012), as the case study approach will provide a deeper understanding of the interplay between people, phenomena and organizations (Weick, 1995, Berg, 2007).

We have selected three main informants and participants of the specific HMP-programme we are interested in for this case study, two women and one man. The criteria for selecting these informants among all of the participants of the actual HMP were that: a) they were participants in the HMP programme; b) had completed this education in about the same time, and c) held a management position in the Norwegian healthcare system in the same municipality. They were therefore expected to have relevant formal knowledge and middle-management experience for this study.

The fact that the three informants were also working in the public healthcare organization in the same municipality made it possible to demarcate and define them in our case study, and enabled us to compare and examine factors that shape the impacts of the HMP on work-life practices, given that several context variables are now held constant, i.e., the size and geographical location of the organizations, the differences of healthcare system needs and operational logic between municipality and county boundaries, etc.

To understand how HMP participation induced changes in behaviour and the leadership style of our three informants, it is not enough to only collect information from our key three informants. The novelty of our research design is that, in addition to these three "protagonists", we also interviewed their superior managers (two persons) and one of the subordinates of each one of them (a total of three persons), all from the same organizational unit our main informants worked at. This makes a total of eight in-depth interviews, as two of the main informants had the same manager. This research design allows us to triangulate the opinions of the main informants with other actors in the same organization and, therefore, to explore the potential effects of the participation in the HMP on the organization, investigated through the personal experience lens (the three previous students), and validated (or not) through the lens of the superior managers and the lens of the subordinates.

\subsection{Data collection strategy and analytical method}

We employed the method of semi-structured in-depth individual interviews with "experience and behaviour questions", "values questions", "feeling questions" and "knowledge questions" (Patton, 2002). The interviews have been transcribed, and from the material we have developed empirical categories used to analyse the data, and relate them to the theoretical categories developed in section 2 .

The first key question is to investigate whether the three main informants (1.1, 2.1, 3.1 in Figure 3 below) have developed or improved skills and changed attitudes on the basis of what they learned in the HMP. In particular, we are interested in two types of "behavioural changes"': a) "Leadership development", and b) "change of daily practices and routines".

Figure 3 exhibits the interviewees and their position within the municipality healthcare organizations. We have defined the middle tier as the HMP participants, the top tier as their managers and the bottom tier as the coworkers/subordinates. 


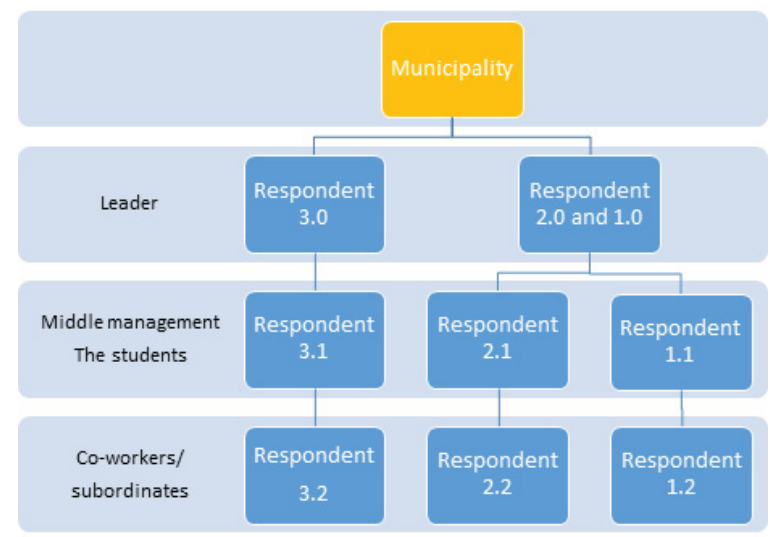

Figure 3: Overview of respondents

Patton (2002) describe different types of questions that apply to most topics. All the respondents were a subject of an introduction, and asked about "background information". On an individual level, it was age and how many modules they had finished, while on an organizational level it was about their position within the organization. Regarding "experience and behaviour questions", we have, e.g., asked about changes in behaviour and routines and what has changed. The main respondents replied regarding their own opinions about their work, with their managers and subordinates also asked about observed changes in behaviour. "Opinion and values questions" are primarily about how the HMP has met their expectations. One example of a "feeling question" is what the HMP has contributed with regarding how they feel in their work situation, with "knowledge questions" targeting what they have learned, both from the main respondents' perspectives and how the managers and subordinates perceive it. We have focussed on the past and the present in the interviewing. The table below is modified from Patton's "Matrix of Question Options" (Patton, 2002).

Table 1: Types of questions asked of the eight interviewees. Numbers indicate the code number of the interview from Figure 3

\begin{tabular}{|l|l|l|}
\hline \multicolumn{1}{|c|}{ Question focus } & \multicolumn{1}{c|}{ Past } & \multicolumn{1}{c|}{ Present } \\
\hline Behaviors/experiences & $1.1,2.1,3.1$ & All respondents \\
\hline Opinions/values & & $\begin{array}{l}\text { All respondents: } \\
\text { Students (1.1,2.1,3.1): own opinions } \\
\text { tied to own situation } \\
\text { Leaders: (1.0,2.0,3.0) opinion on } \\
\text { function regarding main respondents } \\
\text { Subordinates: (3.2, 2.2, 1.2) opinion } \\
\text { on function regarding main } \\
\text { respondents }\end{array}$ \\
\hline Feelings/emotions & & $1.1,2.1,3.1$ \\
\hline Knowledge on leadership & & All respondents \\
\hline Background information (individual) & All respondents & $\begin{array}{l}\text { All respondents (age and finished } \\
\text { modules) }\end{array}$ \\
\hline $\begin{array}{l}\text { Background information } \\
\text { (organization) }\end{array}$ & & $\begin{array}{l}\text { All respondents (position within } \\
\text { organization) }\end{array}$ \\
\hline
\end{tabular}

\section{Case description}

The Norwegian Directorate of Health required that a large number of the management staff in the healthcare system should undergo a management training programme specifically designed for that sector. The Inland Norway University of Applied Sciences (HINN), together with Fagakademiet and "The Resource Centre for Reorganization in Municipalities" (translated from the Norwegian: "Ressurssenter for omstilling i kommunene"), won the tender.

These managers are to lead complex organizations that have high expectations regarding cooperation and collaboration across different subject areas, in addition to interactions between their workplace within a municipality and the specialist health service. On the local level, it is about recruiting, adapting for a healthy work environment and utilizing and deploying resources accordingly. More concretely, it is about the management of empowered workers, the development of competencies, the development of quality in the 
organization, the development of management skills, and last but not least, about how to establish and promote collaboration among the various actors within the healthcare services.

The education was decided to be offered in the municipalities where the students worked. It was the lecturers, not the students who travelled to the teaching venues. The educational programme that our respondents have been a part of consisted of eight modules of 7.5 ECTS. The study is seminar-based, with one of the requirements being to utilize the students' workplaces as a living laboratory, thereby generating illustrative examples and case exercises during the study period.

Our three main respondents are from the same municipality and same healthcare division, but from three different departments: home care, nursing home - long term and nursing home - short term. During their study period, they formed a group of three that studied together and had group exams, which has been important for them in their learning process.

\section{Results and discussion}

\subsection{What were the main experiences from the Health Manager Programme?}

We find that there was an established demand for more education when the HMP presented an offer to the health managers in the municipality. According to the unit managers (see Figure 3), there were high expectations in the organization, as this was what the middle managers needed to better accomplish the challenges of change processes and ongoing projects within the organization (respondent 1.0, respondent 3.0).

The three previous students were all trained nurses with a long work experience, and two of them had already worked for some years as middle managers. The third was new in the job as a manager at the time, and needed additional management education to better cope with the work (respondent 3.1). Two of the students expressed that they had asked for and been promised an HMP education (respondent 2.1., respondent 3.1). According to the health division manager (respondent 1.0), there was a demand for competence on the management level for handling work challenges, as well as a need for individual development as a manager. The third student joined the education after being persuaded by the leader (respondent 3.1).

The overall impression is that all three respondents were satisfied with the learning outcomes of the HMP. They claim that they could now exercise more autonomy and feel more competent due to their adult education. The three former students all reported to have worked well together as a group, and achieved top results (respondent 3.1). We find that the majority of the eight modules in the HMP were rated as of high relevance and quality standards. There were some negative comments, such as the one about one of the lecturers not being up-to-date on the regional project concerning welfare technology. Another area of discontent was the long time (four years) it took from the start to the finish of the study programme. According to one of the respondents, it took some pressure from the participants to make the responsible providers offer the last module to complete the programme (respondent 3.1).

In particular, all three former students point out the relevance of two modules in the HMP. "Planning, Management, and Development of Strategic Competence" has been very useful, as they could use the course content directly into their work as middle managers and project leaders. Likewise, the interviewees have found useful knowledge from the first module, "Management of Empowered co-workers and development of personal leadership skills".

Their superior managers also confirmed that overall the three former students seem to have learned a lot from the HMP study programme (respondent 1.0, respondent 3.0). They point out that two of them have also shown that they have taken new responsibilities in their work. The third former student claims to have learned a lot: "I use the curriculum ...to confer for guidance" (respondent 1.1), whereas the manager and subordinate did not see much change in managerial practice (respondent 1.0, respondent 1.2). The subordinate expresses: "I really should have wished that - my leader would have shared more of the experiences from the HMP" (respondent 1.2).

The former students, their managers and subordinates all agree on the positive outcome of the HMP. They express having high expectations and high standards for themselves and their work. As described by Eccles (Eccles, 2014, Wigfield and Eccles, 2000), their performance has been successful regarding their education as 
they got top grades, according to respondent 3.1. Since the education is done in parallel to working full time, it is an achievement just to finish. This is in line with Atkinson's Achievement Motivation (Atkinson, 1957), as they have an incentive value to achieve success. They want to achieve good grades, and they have high expectations regarding the outcome for the HMP. This can also be explained by Bandura's theory on selfefficacy (Bandura, 1986, Bandura, 1997), as this is about having capabilities to learn or achieve at a certain level.

Both the former students and their superior managers claim that the education (HMP) has provided them with tools (e.g. strategic competence planning skills and project management skills) to handle their work as administrators and as managers for subordinates. Through understanding that the education (HMP) provides tools and empowers the students as managers, they have experienced the relevance of the study. They understand how they could personally associate the learning to their own work situation, see the usefulness as middle managers and identify with the content of the HMP (Priniski, et al., 2018).

\subsection{What were the respondents' learning outcomes of HMP?}

Regarding the development towards being reflective practitioners in their role as leaders, the former students all report on a positive outcome.

The HMP was designed as a practice-oriented programme, in which one of the requirements was that the students were to bring in their own workplace experiences and cases to the classes. According to the former students, one of the most important activities during the study programme was the discussions and reflections in groups with other students. Reflection was a central part of education. The possibility of suggesting cases and experiences from their own practices, and reflecting upon them, gave new insight that they could bring back to their workplace. This is also accentuated as an advantage when working together with the group exams; because of their good cases and thorough group work, they got good grades. "We were three [persons] working in group-exams together... sharing experience... a lot of learning in group tests, when the group works well" (respondent 3.1) (respondent 2.1).

The advantage of the students having the same background and thus being able to understand, share and discuss their experiences, has also been pointed out (respondent 1.1). This also led to the development of a local network, as all the former students (in our study) emphasized the benefit of being a group of three from the same municipality. During the study period, they got to know each other on a more personal level, and could more easily discuss matters of common interest and importance with their fellow colleagues. This is confirmed by statements like: "We have written assignments together and we have reflected and have become a good team, you know. We have become closer than before" (respondent 1.1).

As a result of the HMP, the three interviewees report that their respective departments introduced weekly reflection meetings with the entire staff, to have time to discuss and reflect on problems and issues regarding their work practice. Likewise, the top management group is having monthly meetings with a reflection point on the agenda. These are maybe small changes, but they indicate a development towards a learning organization.

To meet with other students from the region during the HMP education contributed to building a network with other health managers, which is useful when working in health projects across the region (respondent 2.1).

Through working on their assignments, they need to reflect upon solutions, reflect on the feedback and adjust according to the feedback and their reflections upon the feedback. This resembles Kolb's experiential learning cycle (1984), as most of this cycle describes a reflection on action and planning for new action based on the reflections.

Since they also have an opportunity to "bring the learning" to their work and "put the learning to work", they also have an opportunity to reflect before action (Cowan, 2006), reflect "in action" as described by Schön and even reflect "in action on action" (1987).

The respondents display different kinds of reflection. Above is an example of the retrospective reflection, and they also show self-reflection and a reflection for improvement as explained by Ghaye (2011), as they are 
reflecting on their own activities in order to improve their work and function better as middle managers. They attend the HMP in order to become better at their jobs, and become better middle managers. As a result, the reflective learning reflects the learning as a result of the reflection that Moon (2004) refers to.

We have found that their recurring reflection on their own practice in and during the study programme has enhanced their reflective practice back into their workplace. This has had an impact on their execution of leadership, as they have introduced more reflections in their daily work. Hence, this indicates a new and improved KM practice in their workplace.

\subsection{Leadership development}

Being a middle manager is about coping with many different tasks. It is about being an administrator of the daily work and handling the staff. It is also about being a facilitator and change maker who helps organize for the subordinates when it comes to trying out new ways to work. This is in addition to being a translator when it comes to presenting and making sense to the staff on the necessity of changes and challenges, and having sustained their ability to communicate (Hope, 2015).

Our material shows that the three previous HMP students all find that going through with the HMP has changed them. They have learned a lot and developed as leaders. The three respondents, two females and one male, were all health managers with a long experience as trained nurses. They were quite similar when it comes to education, work experience and age. In conducting their daily job, they did similar tasks, but we also find that their work performance differed somewhat, according to what they themselves and their managers/subordinates reported.

One of the former students expressed change: "I became more conscious about the role of a manager than I was before.... d didn't see myself as a leader, more like an administrator, in a way" (respondent 1.1), although this is not the opinion of the surroundings (respondent 1.0, respondent 1.2.). There is a difference between respondent 1.1's self-perception, and how the manager and subordinate perceive it. The data are not conclusive and yet they point towards the four-phase model by Hidi and Renninger (2006), in which the interest in the subject has come gradually and is still evolving. Within Priniski, et al.'s (2018) model, the respondent identifies with the curriculum, but has not yet been able to fully explore the potential of the learning back in the organization.

The other former student expressed that: "Education has given me new strength as a person." Having gone through with the HMP, the respondent claims to be taken more seriously, has more influence and is invited to participate in more interesting work projects (respondent 2.1). This "new strength as a person" and engagement outside the organization point towards seeing the personal usefulness, personal association and personal identification regarding the curriculum (Priniski, et al., 2018).

The third respondent was relatively new as a manager, and felt the need for role development and for having a more formal management education. The respondent reports: "It has been a boost in many ways - but most important for me is to feel more confident in the role" (respondent 3.1). The HMP has brought both new knowledge and a chance to develop as a leader, leading to feeling more confident as a manager. This was confirmed by the superior manager: [the respondent] "is more conscious about being a leader.... and has gotten a deeper understanding of leadership" (respondent 3.0). The subordinate's notion is: "The education has changed the way of being more straightforward as a leader" (respondent 3.2).

One of the respondents had this self-description: "As a person I'm very efficient", and "struggle when things tend to take too much time" (respondent 2.1). In spite of this, the respondent claims to have managed to motivate the staff to take more responsibility, even if this (at times) can be less efficient, and an expression that confirms this being: "It used to be the managers' job to fix everything"... "now everyone has a responsibility to contribute" (respondent 2.1). Our data show that the respondent motivates the staff and shares information, which is a part of how to execute EL (Amundsen and Martinsen, 2014, Amundsen and Martinsen, 2015). How to motivate and share information is a part of what is taught as a part of democratic leadership (Woods, 2005). We also find that the respondent initiates change, and shows innovativeness regarding putting ideas into motion. This may be interpreted as a response to the $\mathrm{EL}$, which enables them to make use of the new knowledge on executing leadership (Amundsen and Martinsen, 2014, Amundsen and Martinsen, 2015, Kim, et al., 2018). 
Respondent 3.1 has assumed the role as a facilitator for change, and accentuates: "If you want to change something, the staff has to contribute, too, they have to have the ideas and feel the need for change." "So, I am responsible for organizing for the subordinates when it comes to trying out more systematically new ways of practice in their daily work" (respondent 3.1). Again, this is a clear indication of executing EL by assuming the responsibility of making the subordinates being able to change practice (Kim, et al., 2018, Amundsen and Martinsen, 2014, Amundsen and Martinsen, 2015). It is about empowering the staff. Respondent 3.1 is also very concerned with strategic competence management and disseminating knowledge, who emphasizes informing subordinates and sharing knowledge. These are KM practices supporting information sharing and dissemination (Nisula and Kianto, 2016, Kianto, 2019, Andreeva and Kianto, 2012, Andreeva and Kianto, 2011). Thus, the respondent seeks to allocate resources among the subordinates, and is concerned about their personal mastery (Lai, 2013, Senge, 1992, Davenport, 1998).

All respondents display an understanding of their roles as managers, which they claim to have developed through their study programme. For example, we can assume that the courses on "Management of Empowered Co-workers" and "Development of Personal Leader Skills" have led to a greater awareness about the leadership role. Even if the former students all claim to have learned from the courses, they seem to have reached different levels in their development as middle managers.

We find that there are some differences in how the three respondents perceive their role as a manager, and how this inflicts on their job performance. Two of them are more proactive, take initiative and are oriented towards change, and willing to take responsibility in change processes. The third is more cautious, almost conservative when it comes to changes. A possible explanation to the differences may lie in the level of confidence and sense of self-efficacy (Bandura, 1997, Bandura, 2012). Even if they all have experienced an identification with the EL, there still may be a difference in the execution of EL (Amundsen and Martinsen, 2014, Amundsen and Martinsen, 2015, Kim, et al., 2018). There may also be a different level of confidence regarding testing out the learning, and continuing learning back in the organization by testing out the new knowledge (about empowering the subordinates). The informal part of the learning is therefore not prominent (Filstad, 2016, Filstad and Blåka, 2007).

The HMP has had an impact on their roles as leaders, even though they have different ways of executing their leadership, which we will look further into in the section below.

\subsection{In what way have the respondents changed their daily practice as leaders?}

A central part of being a middle manager is being able to communicate with their staff. The previously mentioned enhanced reflection processes are a part of enabling communication and empowerment.

An example to show how respondent 2.1 has changed the daily practice when dealing with the staff: "I have had to communicate to the staff the importance of empowerment, and that they need to assume more responsibility. This is a change from my earlier leadership practice" (respondent 2.1) The staff is expected to take more responsibility for the working environment, and for keeping the routines without being reminded. The respondents' notion on the staff reaction is that at first: "They want everything to be like it always has been... Not all of them want to be empowered, you know" (respondent 2.1). This may be a resistance to change (Irgens, 2011, Hayes, 2002).

Gradually, the staff finds out that this is not bad, but that it is fun take responsibility, to try out things and to obtain positive feedback (respondent 2.1). They seem to have followed Hayes' curve, showing the resistance to starting in "shock", and over time ending up in a state where they are going along with the change (Hayes, 2002). The subordinate interviewee also confirms that the manager is present in their reflection meetings, challenges the staff, is responsive and makes decisions based on discussions in the group of the staff (respondent 2.2). The reflection of the previous students (middle managers) serves as an important part of the learning process (Schön, 1987, Schön, 1991). The responsiveness and inclusion of the subordinates again point towards the execution of EL (Amundsen and Martinsen, 2014, Amundsen and Martinsen, 2015, Kim, et al., 2018).

Respondent 3.1 reports that the subordinates have noticed that the respondent has attended an education: "It has to be the change in the ways of working and of being systematic in developing competence and to stress the need for quality.... And also working with empowering the staff... they shall have the competence and feel 
safe regarding their job execution, and develop their potential resources" (respondent 3.1). This informal part of the learning process (Filstad, 2016) is important to work on executing the empowering leadership (Amundsen and Martinsen, 2014, Amundsen and Martinsen, 2015). The subordinates recognize the takes on EL and can describe them.

From the subordinates' point of view, this manager has also changed the way of dealing with the staff after going through the HMP. "Have noticed changes, for instance, when we are supposed to work more independently, we get more responsibility at work" (respondent 3.2). When questions are raised, the manager gives the staff the responsibility to find the answers or solutions by themselves, instead of taking the lead. By this, the respondent is empowering the staff, while at the same time backing them in a way that makes them feel that they succeed (Amundsen and Martinsen, 2015, Amundsen and Martinsen, 2014, Kim, et al., 2018). The subordinate also speaks well of the manager as a good leader when it comes to support for returning to work after periods of sick leave. The manager was both supportive and firm (respondent 3.2). This implies that they are performing well in their job as empowering leaders. Their practice has "paid off" and their formal and informal learning (Filstad, 2016), including the reflection processes (Schön, 1987, Schön, 1991), have over time developed the primary respondents' leadership styles (Amundsen and Martinsen, 2014, Amundsen and Martinsen, 2015).

Respondent 3.1 emphasizes work with knowledge development and sharing. Competence planning is systematically used to develop and take advantage of the competence in staff. The subordinates are supported when testing new ideas, as well as when they show innovativeness. "Everyone shows interest in sharing knowledge, it's spreading like ripples in the water". The respondent claims that there is a culture for knowledge sharing in the department (respondent 3.1). Competency planning is a part of the KM practices (Andreeva and Kianto, 2012, Andreeva and Kianto, 2011, Nisula and Kianto, 2016, Davenport, 1998), and it is also their contribution towards developing a learning organization (Filstad, 2016, Irgens, 2011, Lai, 2013).

We find that two of the leaders have made changes, making the subordinates take more responsibility for solving the day-to-day problems, which seems to be under the influence of the HMP.

The third claim is to having learned a lot from the education, which is useful in the daily work. The nearest leader and subordinate find there are little changes to the ways of behaviour as a manager, although weekly staff meetings with organized reflection have been introduced as in the other departments. The respondent is a responsive leader, who often asks the subordinates for feedback, and listens to their views on matters such as the work plan, which is seen as a positive trait (respondent 1.3).

Encouraging the subordinates to work independently is about providing them with a sense of autonomy, and to support them regarding competence and relatedness. This support towards being more effective and mastering their task is a predominant characteristic of the Self-Determination Theory (Ryan and Deci, 2017). The positive reinforcement leads to commitment and energy, even though our subordinate respondents (respondents $1.3,2.3,3.3$ ) also show signs of resistance to change. However, involvement and engaging subordinates generally results in a higher degree of commitment among the workers (Knowles, 1984, Nonaka, 1994).

The middle managers are able to support and develop intrinsic job motivation with the subordinates, as they have developed their skills within empowerment leadership (two of the main respondents more than the other). By the way, this is shown that they include the subordinates in the reflection processes and the change processes. The middle managers have all learned about EL, but not all have maximized the learning process by implementing the EL back in their workplace (Filstad, 2016).

\subsection{What is the impact of the HMP in an organization? The development of KM practices}

We find that there have been changes in the KM practices in all three healthcare departments previous to- and after the participation of our three respondents in the HMP. Evidence from the discussion above suggests that the HMP had the following impacts on the three departments:

- the introduction of more systematic and reflective cognitive activities regarding the organization and management;

- a more systematic competency planning;

- a more active knowledge sharing; and 


\section{- $\quad$ a leadership style more towards the direction of Empowering Leadership.}

Since education within healthcare (nursing education, etc.) contains a substantial amount of training in becoming reflective practitioners, we can assume that they have been doing some form of reflection processes prior to their education at HMP. However, the evidence of an enhanced and more encompassing and systematic reflection is claimed by the respondents, their superiors and their subordinates.

Based on the results above, we also discuss the impact of the HMP within the organization, and how this has affected the development of the KM practices. The formal education that the HMP represents has provided the students with the tools and knowledge to further develop informal arenas back at the workplace. Through the HMP, the students have acquired tools and developed strengths to aid them in the process of becoming better at their jobs as middle managers, and clearer in their communication.

A requirement for all the students at the HMP is to bring their own practice into the learning, and thus make it situated. Our findings show that utilizing the students' work-life situations as a basis for the case-based part of the learning processes at the HMP strengthens the learning process back at the workplace. When Raelin (2008) discusses work-based learning, he claims that this is different from formal learning. The "conscious reflection on actual experience" is not a part of the formal education, claims Raelin (2008). Even so, we do see the opposite when using the students' own background and work-life when developing cases.

This contributes to establishing relevance, not only for the individual, but also for the workplace, as the students are able to project the discussed solutions back in their work situation.

Our material shows that the formal learning at the HMP is continuing as informal learning back at their workplace. Filstad's (2016) model of Formal and Informal Learning (see Figure 2) conditions that the students in formal learning do not also work together, which is the case in our investigations. Her claim of the discontinued learning process between formal and informal learning is probably the most common situation. Yet, this is one of the benefits for the HMP; the co-learners at the HMP are the same as the co-workers (and, hence, the co-learners) back at the workplace. Even if the co-workers are in different departments, they are under the same employer, and have access to co-reflecting processes. This also strengthens them in their process of facilitating reflection and learning processes for- and together with their subordinates.

The synergy of the formal learning (at the HMP) and informal learning (at the workplace) has contributed to the transformation and implementation of their learning at the workplace, which has strengthened the development of the KM practices. We have established the connection of the HMP regarding enhanced reflection processes and more systematic competency planning. Enhanced reflection processes have also supported KM practices, such as knowledge sharing and development. Our case study showcases that through reflection with peers (co-students) and through practice, the Empowering Leadership has been strengthened and further developed. The figure below (Figure 4) also embraces the important preconditions for these synergies; it is based on theories on adult learning; the students in question (the middle managers) already have a vocational education, and the organization has a high level of maturity regarding learning culture.

Systematic reflections and learning in the organization have supported the culture for learning. The way the students facilitate, and are ideals for their subordinates regarding the competency planning and reflection processes, make it easier to follow up in the organizations and provide the basis for culture for learning, as this is also a managerial issue. The students have seen it as their role as (middle-) managers to facilitate reflection within the organization. A learning culture needs a continuous focus on learning and knowledge development. It is also necessary that the leaders at all levels have a focus on learning which facilitates learning and knowledge development. There is a need for establishing a learning arena that supports and recognizes informal learning between the leader and the subordinates, as well as integrating formal and informal learning (Filstad, 2016). Through establishing the reflections, the leaders are also facilitating learning and knowledge sharing among the subordinates. The management has encouraged the development of a learning arena on several levels. However, learning needs a focus and a goal (Filstad, 2016).

Still, it is not only about changing the KM practices, but also about how the subordinates perceive and interpret the new KM practices (Kianto, 2019). 


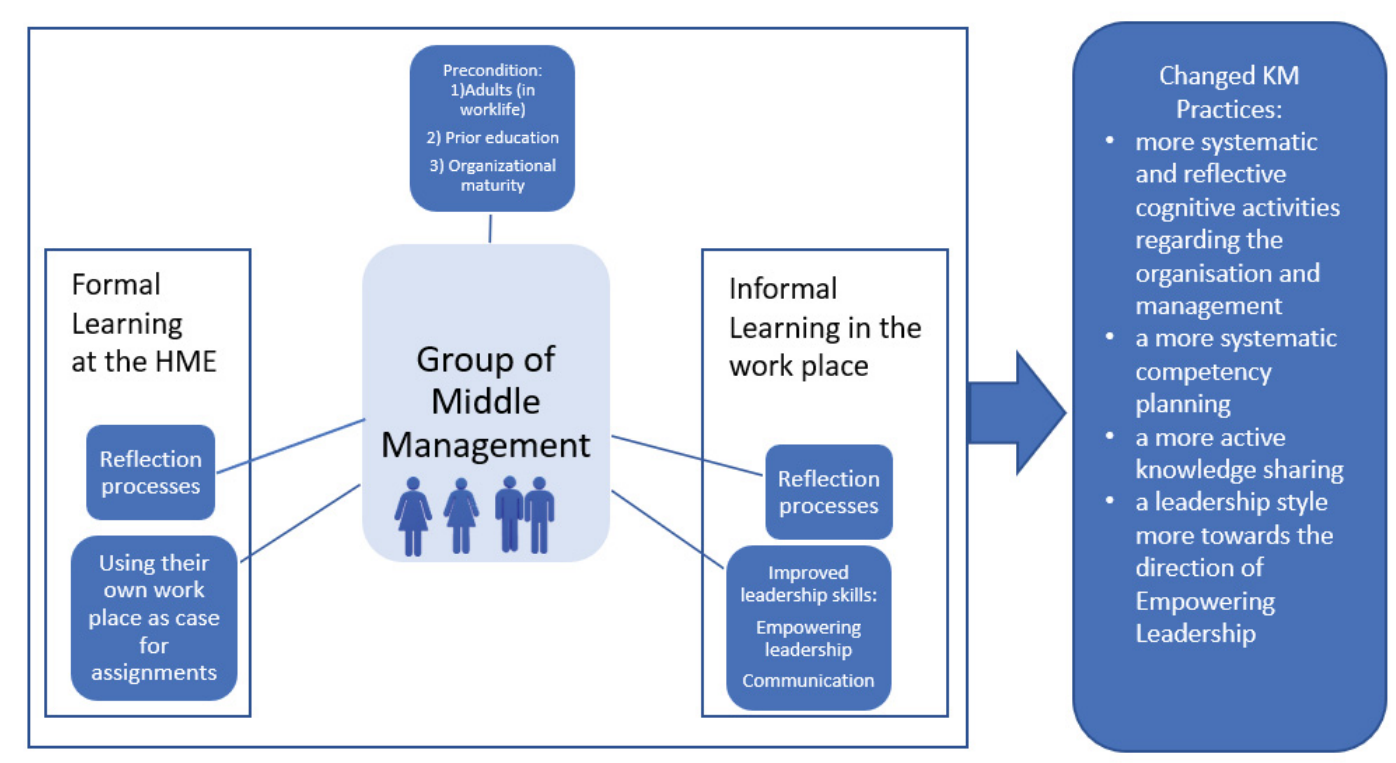

Figure 4: The different aspects of the relevance of HMP: Changed KM practices, processes and outcomes

One major advantage our students have is that they have experienced a prior education; hence, they know how to transform this into an advantage for the organization (Filstad, 2016).

Leadership development, communication and empowerment are key factors that meet the requirements for them, and what is expected of them. The expectations from the managers above are about executing leadership at the middle management level. They have the skills, the abilities and the position, and it is expected of them. The students also have expectations regarding being able to utilize their education (Eccles, 2014, Wigfield and Eccles, 2000), which will bring them into a better position to apply the wanted changes. Through their behaviour as managers, they execute systematic KM practices.

The degree of relevance of the education seems to correlate with how one has used the case examples from the students' work-life and practice in the study through assignments and reflection exercises. In turn, this will be carried on as a reflection and learning praxis back in the organization.

Within the scope of changed KM practices, we can also derive that they have developed innovativeness. We find that because of the way the students execute their new management skills, the subordinates have been subjects of autonomy that support innovativeness. What can be compared to empowered leadership (Amundsen and Martinsen, 2014, Amundsen and Martinsen, 2015) implies supporting the subordinates to develop autonomy, and the sense of being empowered, both of which are necessary in order to develop innovativeness (Støren and Arnesen, 2016, OECD, 2010).

\section{Conclusion}

We have provided evidence showing how HMP is a relevant formal adult education programme for middle managers and their organizations in Norwegian healthcare. On the individual level, the former students (middle management) have shown a high motivation and assertiveness regarding their education. According to their managers and subordinates, their job execution has changed, although in different ways. Through establishing systematic reflective processes and competency planning, they have developed a management practice in line with Empowered Leadership (Amundsen and Martinsen, 2014, Amundsen and Martinsen, 2015). This has further opened the opportunities for the subordinates to actively engage and contribute toward a higher level of innovativeness within the organization (Støren and Arnesen, 2016).

We find that the education has had relevance at the individual and organizational levels, as it has increased the knowledge on the competence planning and knowledge sharing of middle management, and enabled the change of KM practices within the organization. This counts for two out of three of the managers who have changed their attitude towards their subordinates, and are more conscious about involving and empowering their staff. 
To generalize our findings beyond the scope of HMP and the healthcare sector, we may assume that educational programmes, such as the HMP, are of considerable relevance for the work-life provided that distinguishes individual qualities, skills and competences at work, which are also appreciated and in demand. More specifically, we need to remind the reader that our results and conclusions depend on the following analytical preconditions that shape the empirical evidence, and therefore the findings of this study:

1. The students attending the HMP programme are adults, and the learning situation is adapted to theories of adult learning, such as grounding the education on the students' own work-life situations.

2. The students have a previous vocational formal higher education.

3. The organization is receptive and adaptive to changes, and in particular to public sector innovations (high level of maturity regarding changes).

The relevance is experienced through the interconnectedness, such as, e.g., reflection processes between the formal and informal learning processes, which is displayed through the development and change of KM practices.

\section{Acknowledgements}

We would like to extend our thanks to Professor Aristidis Kaloudis, NTNU, Norway, for his valuable input and discussions.

\section{References}

Amundsen, S. and Martinsen, O. L., 2015. Linking empowering leadership to job satisfaction, work effort, and creativity: the role of self-leadership and psychological empowerment.(Report), 22(3), p. 304.

Amundsen, S. and Martinsen, $\varnothing$., 2014. Empowering leadership: construct clarification, conceptualization, and validation of a new scale. Leadership Quarterly, 25(3), p. 487.

Andreeva, T. and Kianto, A., 2011. Knowledge processes, knowledge-intensity and innovation: a moderated mediation analysis. Journal of Knowledge Management, 15(6), pp. 1016-1034.

Andreeva, T. and Kianto, A., 2012. Does knowledge management really matter? Linking knowledge management practices, competitiveness and economic performance. Journal of Knowledge Management, 16(4), pp. 617-636.

Argyris, C. and Schön, D. A., 1978. Organizational learning: a theory of action perspective. Reading, Mass: Addison-Wesley. Atkinson, J. W., 1957. Motivational determinants of risk-taking behavior. Psychological Review, 64(6), pp. 359-372.

Bandura, A., 1986. Social foundations of thought and action: a social cognitive theory. Englewood Cliffs, N.J: Prentice-Hall. Bandura, A., 1997. Self-efficacy: The exercise of control. New York: Freeman.

Bandura, A., 2012. Social cognitive theory.

Berg, B. L., 2007. Qualitative research methods for the social sciences, 6th ed. edition. Boston: Pearson.

Cowan, J., 2006. On becoming an innovative university teacher: reflection in action. Buckingham: Society for Research into Higher Education \& Open University Press.

Davenport, T. and Prusak, L., 1998. Working knowledge: how organizations manage what they know. Harvard Business School Press.

Davenport, T. and Prusak, L., 2000. Working knowledge. Boston, MA.

Deci, E. L. and Ryan, R. M., 1985. Intrinsic motivation and self-determination in human behavior, 1st ed. 1985. edition [eBook]. New York, NY: Springer.

Dewey, J., 2005. Democracy and education. USA: Promethean Press.

Donate, M. J. and Sánchez de Pablo, J. D., 2015. The role of knowledge-oriented leadership in knowledge management practices and innovation. Journal of Business Research, 68(2), pp. 360-370.

Eccles, J., 2014. Expectancy-value theory [Liner notes]. In: Encyclopedia of Sport and Excercise Psychology [1]. 2014.

EUROSTAT, O., 2005. Oslo Manual. Guidelines for collecting and interpreting innovation data.

Fezile, O. and Gulsum, A., 2016. Flipped classroom approach. World Journal on Educational Technology, 8(2), pp. 98-105.

Filstad, C., 2016. Organizational Learning: - from knowledge to competency (in Norwegian: Organisasjonslæring - fra kunnskap til kompetanse), 2. utg. edition. Bergen: Vigmostad \& Bjørke.

Filstad, C. and Blåka, G., 2007. Learning in organizations. Oslo: Cappelen.

Geertz, C., 1973. The Interpretation of cultures. New York: Basic Books.

Ghaye, T., 2011. Teaching and learning through reflective practice: a practical guide for positive action. London: Routledge.

Hayes, J., 2002. The theory and practice of change management. Houndmills, UK: Palgrave.

Henttonen, K., Kianto, A. and Ritala, P., 2016. Knowledge sharing and individual work performance: An empirical study of a public sector organisation. Journal of Knowledge Management, 20(4), pp. 749-768.

Hidi, S. and Renninger, K. A., 2006. The four phase model of interest development. Educational Psychologist, 41(2), pp. 111127.

Holtskog, H., 2014. How industry makes knowledge:facilitative management. 2014:208 Norwegian University of Science and Technology, Faculty of Social Sciences and Technology Management, Department of Industrial Economics and Technology Management. 
Holtskog, H., Carayannis, E. G., Kaloudis, A. and Ringen, G., 2018. Learning factories: the nordic model of manufacturing, 1st ed. 2018. edition [eBook]. Cham: Springer Palgrave Macmillan.

Hope, O., 2015. The Middle Manager (Translated from Norwegian: Mellomlederen). Oslo: Gyldendal akademisk.

Irgens, E. J., 2011. Dynamic and learning organizations: managment and development in a changing worklife. Bergen: Fagbokforl.

Jacobsen, D. I., 2019. Middle management - a special kind of management (translated from Norwegian: "Mellomledelse en spesiell form for ledelse?"). Magma, 22(2), pp. 46-54.

Kianto, A., 2019. Contingencies and complexities of the knowledge-performance relationship, European Conference on Knowledge Management. Lisboa, Portugal: ACPIL.

Kianto, A., Vanhala, M. and Heilmann, P., 2016. The impact of knowledge management on job satisfaction. Journal of Knowledge Management, 20(4), pp. 621-636.

Kim, M., Beehr, T. A. and Prewett, M. S., 2018. Employee responses to empowering leadership: a meta-analysis. Journal of Leadership \& Organizational Studies, 25(3), pp. 257-276.

Kirkpatrick, D. L., 1998. Evaluating training programs:tThe four levels, 2nd ed. edition. San Francisco, Calif: Berrett-Koehler.

Kirkpatrick, D. L. and Kirkpatrick, J. D., 2005. Transferring learning to behavior: using the four levels to improve performance, 1st ed. edition [eBook]. San Francisco, CA: Berrett-Koehler Publishers.

Knowles, M. S., 1970. The modern practice of adult education: andragogy versus pedagogy. New York: Association Press.

Knowles, M. S., 1984. Andragogy in action. San Francisco: Jossey-Bass.

Knowles, M. S., Holton, E. F. and Swanson, R. A., 2005. The adult learner: the definitive classic in adult education and human resource development, 6th ed. edition [eBook]. Amsterdam; Boston: Elsevier.

Kolb, D. A., 1984. Experiential learning: experience as the source of learning and development. Englewood Cliffs, N.J.: Prentice-Hall.

Lai, L., 2013. Strategic Competence Management (from Norwegian: Strategisk kompetanseledelse). Bergen: Fagbokforl.

Lave, J. and Wenger, E., 1991. Situated learning -ILegitimate peripheral participation. Cambridge: Cambridge University Press.

Merriam-Webster, Mastery, 2020. Springfield, Massachusetts, USA: Merriam-Webster.

Moon, J. A., 2004. A handbook of reflective and experiental learning: Theory and practice. London: RoutledgeFalmer.

Nisula, A.-M. and Kianto, A., 2016. The role of knowledge management practices in supporting employee capacity for improvisation. The International Journal of Human Resource Management, 27(17), pp. 1920-1937.

Nonaka, I., 1994. A dynamic theory of organizational knowledge creation. Organization Science, 5(1), pp. 14-37.

Nonaka, I. and Takeuchi, H., 1995. The knowledge-creating company: how Japanese companies create the dynamics of innovation. New York: Oxford University Press.

Nonaka, I. and Takeuchi, H., 2019. The wise company: how companies create continuous innovation. Oxford: Oxford: Oxford University Press USA - OSO.

NOU 2019:12, 2019. Sustainable development of learning: lifelong learning for adaptive change and competitive advantages (Translated from Norwegian: Lærekraftig utvikling: livslang læring for omstilling og konkurranseevne). 9788258314056. Oslo: Department of Government Services.

Næss, T., Støren, L. A. and Kaloudis, A., 2009. Lifelong learning and work-related training in Norway - an international perspective. NIFU-STEP.

OECD, 2010. Innovative workplaces: making better use of skills within organisations.Paris, France: OECD.

Patton, M. Q., 2002. Qualitative research \& evaluation methods. USA: Sage.

Priniski, S. J., Hecht, C. A. and Harackiewicz, J. M., 2018. Making learning personally meaningful: a new framework for relevance research. The Journal of Experimental Education, 86(1), pp. 11-29.

Raelin, J. A., 2008. Work-based learning: Bridging knowledge and action in the workplace, New and rev. ed. San Francisco: Jossey-Bass.

Remenyi, D., 2012. Case Study Research: The Quick Guide Series. Reading: Academic Conferences Publishing International.

Roberson, R., 2013. Helping Students Find Relevance, Psychology Teacher Network 23, 22013.

Rogers, C. R., 1969. Freedom to learn. Colombus, Ohio: Merrill.

Ryan, R. M. and Deci, E. L., 2017. Self-determination theory:bBasic psychological needs in motivation, development, and wellness [eBook]. New York, New York; London, England: The Guildford Press.

Schunk, D. H., Meece, J. L. and Pintrich, P. R., 2014. Motivation in education: Theory, research, and applications, Fourth, Pearson new international edition. edition [eBook]. Essex, England: Pearson.

Schön, D. A., 1987. Educating the reflective practitioner. San Francisco: Jossey-Bass.

Schön, D. A., 1991. The reflective practitioner: How professionals think in action. Aldershot: Avesbury.

Senge, P. M., 1992. The fifth discipline: The art and practice of the learning organization. London: Century Business.

Senge, P. M., 2006. The fifth discipline: The art and practice of the learning organization, [Rev. and updated]. edition. New York: Currency/Doubleday.

Services, M. o. H. a. C., 2009. The Coordination Reform - Proper treatment - at the right place and right time. 47.Norwegian Ministry of Health and Care Services. [online] Available at: https://www.regjeringen.no/en/dokumenter/report.no.-47-to-the-storting-2008-2009/id567201/ [Accessed 20.12.2019].

Sousa, M. J., 2019. Strategic knowledge management in the digital age: JBR special issue editorial. Journal of Business Research, 94, pp. 223-226. 
Strandquist, M. and Adal, L., 2011. The path to a better health management (Translated from Norwegian: "Veien til bedre helseledelse: IKOS - individbasert kompetansestyring"). Oslo: Kommuneforl.

Støren, L. A. and Arnesen, C. A., 2016. Skills utilisation at work, the quality of the study programme and fields of study. Quality in Higher Education, 22(2), pp. 127-138.

Vold, A. T., Ranglund, O. J. S., Haave, H. M., Kiønig, L. V., Venemyr, G. O., Lervik, M. J., Bakken, B. T., Bergum, S., tHolen, S., Granlien, P., Klevhus, H. and Klevhus, A., 2017. Flipped gaming: the teachers role when using the students as content providers, The European Conference on Games Based Learning. Graz, Austria: ACPIL.

Vold, T., 2014. How can the concept of "Flipped Classroom" support the development of reflective practitioners in higher education?, ITHET2014. York, UK: University of York, UK.

Vold, T., Braun, R. and Lundesgaard, D. D., 2016. Flipped classroom - students as producers, In IEEE (ed.), 2016 15th International Conference on Information Technology Based Higher Education and Training (ITHET) [eBook]. Istanbul, Turkey: IEEE.

Vold, T., Haave, H. and Kaloudis, A., 2020. On Work Relevance of Adult Education: a Case Study Narrative. Electronic Journal of Knowledge Management: EJKM, 18(2), pp. 105-120.

Von Krogh, G., Ichijo, K. and Nonaka, I., 2000. Enabling knowledge creation:hHow to unlock the mystery of tacit knowledge and release the power of innovation. Oxford: Oxford University Press.

Weick, K. E., 1995. Sensemaking in Organizations. Thousand Oaks, CA: Sage.

Wigfield, A. and Eccles, J., 2000. Expectancy-value theory of achievement motivation. Contemporary Educational Psychology, 25(1), pp. 68-81.

Woods, P. A., 2005. Democratic leadership in education [eBook]. London: Paul Chapman.

Yin, R. K., 2009. Case study research: Design and methods, vol. 5, 4th ed. edition. Thousand Oaks, CA: Sage.

Yukl, G. A., 2010. Leadership in organizations, 7th ed. edition. Upper Saddle River, N.J: Pearson Education. 